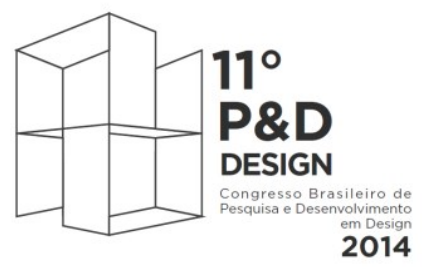

Gramado - RS

De 30 de setembro a 2 de outubro de 2014

\title{
UM RETRATO DOS LIVROS DIGITAIS: desenvolvimento de instrumental metodológico para estudo empírico ${ }^{1}$
}

\author{
Thaís Cristina Martino Sehn \\ UFPel \\ crisehn@hotmail.com \\ Suely Fragoso \\ UFRGS, CNPq \\ suelyfragoso@ufrgs.br
}

\begin{abstract}
Resumo: Este artigo apresenta instrumentos metodológicos desenvolvidos para a caracterização de artefatos que são atualmente chamados de 'livros digitais' em termos de suas apropriações do design editorial e do design digital. Ao descrever o processo de elaboração e os procedimentos adotados, este trabalho tem como objetivo auxiliar outros pesquisadores com desafios metodológicos semelhantes. A construção do instrumento metodológico foi dividida em seis etapas. As duas primeiras foram respectivamente uma codificação aberta e outra axial; a terceira um estudo comparativo entre as versões impressa e digital de um mesmo livro; a quarta e quinta categorizações analíticas; a sexta etapa um refinamento até a versão final do instrumento, o qual foi utilizado para a realização da caracterização dos artefatos considerados 'livros digitais'.
\end{abstract}

Palavras-chave: design, design editorial, livro, e-book, metodologia.

Abstract: This paper presents a methodological toolkit developed for the characterization of artefacts that are nowadays called 'digital books', according to their appropriations of editorial design and of digital design. By describing the process and the procedures adopted, this work intends to be of help for other researchers facing similar methodological challenges. The toolkit was built in six phases: the first and second respectively an open and an coaxial codification; the third a comparative study of the printed and digital versions of the same book; the fourth and fifth were analytical categorizations; the sixth phase refined the previous version of the toolkit up to its final version, which was applied in the study to characterize the artefacts considered to be 'digital books'.

Keywords: design, editorial design, book, eBook, methodology.

\footnotetext{
${ }^{1}$ Este trabalho apresenta resultados parciais de pesquisas apoiadas pela CAPES e CNPq.
} 


\section{INTRODUÇÃO}

Este trabalho descreve os procedimentos para a construção do instrumental metodológico utilizado em um mapeamento e caracterização de artefatos que são atualmente chamados de 'livros digitais', em termos do design editorial e levando em conta os recursos próprios do meio digital. Ao trazer a tona o caminho percorrido para alcançar o objetivo proposto, este artigo tem o intuito de auxiliar pesquisadores que enfrentam as dificuldades da pesquisa empírica e da realização de mapeamentos e categorizações para compreender melhor seus objetos de pesquisa.

O texto não alcança os resultados da categorização propriamente dita, pois seu objetivo é a apresentação dos instrumentos metodológicos desenvolvidos.

\section{MAPEAMENTO}

O mapeamento foi realizado a partir da observação de sites e blogs especializados em e-books, livrarias digitais que comercializam e anunciam o mesmo e, por fim, congressos e premiações da área. Durante um ano e meio esses livros foram armazenados para constituir a base da construção da amostra. Esclarece-se, ainda, que o mapeamento foi constituído de artefatos que estavam disponíveis entre 2011 e 2013. Através da observação das fontes, foram verificadas as sugestões de livros digitais e de outros sites que falavam sobre o assunto. Ao perceber que um e-book poderia ser interessante para a análise, verificava-se as opções de aquisição do mesmo: se gratuito ou à venda. Analisava-se também se este possuía amostra do material e se esta seria suficiente para analisar os recursos utilizados no livro; para quais aparelhos e sistemas estaria disponível etc.

\section{CONSTRUÇÃO DA AMOSTRA}

Para a construção da amostra, partiu-se da pré-seleção realizada no mapeamento, da qual foram selecionados livros digitais informacionalmente ricos, os quais, como explicou Patton (2003, p. 230, tradução nossa), "são aqueles que mais permitem aprender sobre as questões centrais que a pesquisa tem a intenção de endereçar". Outro elemento de seleção foi a preferência - mas não exclusividade - por obras em português, uma vez que a pesquisa está sendo feita no Brasil e o acesso é facilitado nos aparelhos comercializados aqui .

Esse modo de construir a amostra é próprio das pesquisas qualitativas, em que a representatividade estatística é menos importante que a obtenção de informações de fina granularidade. Nesse tipo de amostra, denominada "emergente" e "intencional" os elementos podem ser "selecionados deliberadamente, conforme apresentem características necessárias para a observação, percepção e análise das motivações centrais da pesquisa" (FRAGOSO, RECUERO; AMARAL, 2012, p. 67). Evidentemente, uma amostra desse tipo não se presta a generalizações: a intenção do estudo não era caracterizar o universo dos livros digitais atuais, mas identificar a presença de recursos próprios do meio digital e seus modos de utilização no design gráfico digital. Pesquisas como essa, de caráter estritamente qualitativo, não precisam de amostras com representatividade estatística, mas de amostras com alto nível de informação. Por isso, para a delimitação do tamanho da amostra foi escolhido o 
processo de saturação, ou seja, como explicaram Fragoso, Recuero e Amaral (2012, p. 95), a amostragem é interrompida quando o pesquisador percebe, com segurança, que "não há mais categorias emergindo ou há uma repetição naquilo que é colocado".

Amostragens por saturação só são possíveis se realizadas em paralelo com as análises - afinal, é preciso saber quando a amostra está saturada, ou seja, quando não há mais informação nova a ser obtida; o que só é possível quando se sabe o que informam os casos que já foram integrados à amostra. As principais balizas de construção da amostra foram aplicadas conforme uma ordem pré-estabelecida que inicialmente abarcou os aparelhos, em seguida os softwares utilizados para a disponibilização dos livros e, finalmente, as peculiaridades das próprias obras. Essa ordem pré-estabelecida permitiu que se chegasse ao ponto de saturação mais claramente, tornando possível identificar o momento em que os recursos e as características dos livros de cada tipo passavam a se repetir.

Foram analisados 82 livros digitais: 16 deles em e-reader; 26 em aplicativos específicos para leitura no tablet; 18 no aplicativo iBooks, nativo do iPad; 26 livrosaplicativos em tablet e 14 em notebook.

\section{CONSTRUÇÃO DO INSTRUMENTO DE ANÁLISE}

A observação e análise foi construída em seis etapas. As duas primeiras, inspiradas na Teoria Fundamentada (TF), foram feitas sobre a codificação aberta e a codificação axial (FRAGOSO; RECUERO; AMARAL, 2012). A escolha pela TF, nesta fase da observação, foi baseada no apelo empírico proposto pela mesma, cuja ideia central é que "a teoria deve emergir dos dados, a partir de sua sistemática observação, comparação, classificação e análise de similaridades e dissimilaridades" (FRAGOSO; RECUERO; AMARAL, 2012, p. 83). Contudo, o trabalho como um todo não se caracterizou como uma pesquisa de TF, pois havia um estudo teórico precedente. A TF apenas inspirou as duas primeiras etapas da análise, que se concentraram mais nas questões técnicas. Com isso, pretendeu-se obter as maiores vantagens da TF, ou seja, a percepção o mais 'pura' possível do objeto estudado e seu universo, sem abrir mão de aspectos que constituem sua desvantagem, sobretudo o fato de que ela implica em um distanciamento da teoria nesse momento da observação. No caso, a partir da terceira etapa de análise, a verificação empírica passou a ser informada diretamente pelo conhecimento teórico sobre design editorial e design digital.

A primeira etapa foi uma 'codificação aberta' - uma pesquisa exploratória para identificação, descrição e categorização dos artefatos vinculados ao livro digital. Posteriormente, numa segunda etapa, foi realizada a 'codificação axial', que permitiu a organização das obras em categorias preliminares, observando-se suas conexões e buscando compreender o que suas características representavam para os leitores e para os agentes envolvidos na produção do livro digital.

A seguir, realizou-se a terceira etapa, que foi uma análise preliminar de um dos livros da amostra, o Reprograme, de Luís Mendes, $2012^{2}$. A escolha recaiu sobre essa obra porque a mesma havia sido lançada em quatro formatos simultaneamente (impresso, PDF, MOBI, EPUB), apresentando diferenças em seus projetos gráficos, impresso e digital, cada qual atentando para as especificidades de seu suporte. A

\footnotetext{
${ }^{2}$ Esta análise resultou em um artigo que está sendo publicado na revista Educação Gráfica, vol. 18, 2014. Disponibilizada em:

<http://www.educacaografica.inf.br/artigos/um-livro-quatro-formatos-as-novas-materialidades-do-conhecimento>.
} 
identificação dessas particularidades foi realizada com base na bibliografia específica de projeto gráfico editorial e com os resultados preliminares obtidos através da codificação axial. Essas duas fontes resultaram em uma primeira tabela de análise ${ }^{3}$ e constituíram a quarta etapa deste processo. A objetividade das características que foram identificadas fez com que essa tabela assumisse um formato semelhante ao de um questionário de múltipla escolha, o que permitiu identificar conjuntos de detalhes, que foram objeto de uma análise mais aprofundada. Esse instrumento foi testado em três estudos-piloto com livros digitais de pré-categorias distintas, cada um dos quais resultando em alterações nas questões de análise.

A partir dos resultados obtidos na quarta etapa, fez-se uma reflexão sobre o objetivo de cada questão, percebendo-se que, em função do detalhamento proposto pelos autores utilizados como fonte teórica, a categorização pendia demasiadamente para as questões do design gráfico, em detrimento das questões do digital. Desse modo, em uma quinta etapa, houve uma reformulação do instrumento de análise ${ }^{4}$, dando-se, então, maior ênfase ao conhecimento sistematizado na codificação axial e potencialidades do meio digital (sem deixar, entretanto, de considerar as bibliografias que versavam sobre design editorial). Esta nova tabela também assumiu o formato de questões múltipla escolha e foi novamente testada em três novos estudos-piloto realizados com outros livros digitais de pré-categorias diferentes. Os estudos-piloto auxiliaram o refinamento desse instrumento, que sofreu alterações.

De posse desses resultados, elaborou-se a tabela final de análise ${ }^{5}$ (sexta etapa), para a qual também foram realizados dois estudos-pilotos, os quais antecederam à análise da amostra. Para esta tabela, inspirando-se no trabalho de Ludwig (2012), os recursos analisados foram divididos em macrocategorias, categorias e subcategorias. Estas foram definidas com base no cruzamento dos elementos da revisão teórica ${ }^{6}$ com as características dos livros digitais percebidas nas etapas anteriores. Os parâmetros foram organizados para obter uma resposta binária (possui/não possui; $1 / 0$ ) para cada item, o que tornou mais fácil a visualização das características de cada um. As macrocategorias de análise criadas foram: Identificação, Acesso, Funcionalidades, Potencialidades do meio digital, Aproximação da ideia de livro impresso (remediação ${ }^{7}$ ) e Projeto gráfico.

Os primeiros itens da tabela, correspondentes à macrocategoria Identificação, destinam-se a identificar e contextualizar os e-books que foram analisados, sendo estes itens os únicos preenchidos com texto. Para a identificação, optou-se por anotar o nome do livro, o autor e a editora (na ausência desta, a empresa responsável) (

\footnotetext{
${ }^{3}$ A tabela foi construída inicialmente na forma de questionário com a ferramenta do Google, a qual seria preenchida pela pesquisadora e os resultados seriam exibidos em forma de tabela. O questionário está disponível no endereço <http://goo.gl/fM4byR> .

${ }^{4}$ Disponível no endereço: $<$ http://goo.gl/3PxWjk>.

${ }^{5}$ Disponível para download em PDF e em arquivo do Excel no endereço: <http://goo.gl/Ge6N38>

${ }^{6}$ Baseada em Bolter e Grusin (2000), Bolter (2001), Bringhurst (2005), Chartier (1997, 1999), Fragoso (2001), Hendel (2006), Landow (2006) e Ribeiro (2010).

${ }^{7}$ Remediação (Remediation) é um conceito criado por Bolter e Grusin (2000) para falar da lógica formal na qual uma mídia é incorporada ou representada em uma nova mídia.
} 
Tabela 1). 
Tabela 1 - Identificação I

\begin{tabular}{ccc}
\hline & IDENTIFICAÇÃo & \\
\hline Nome do livro & Autor & Editora/empresa \\
\hline Xxxxx & Xxxxx & Xxxxx \\
\hline
\end{tabular}

Fonte: Elaborado pelo autor, com base na pesquisa realizada.

Para a contextualização da análise, foram indicados os seguintes itens: o formato ${ }^{8}$ do arquivo, o software utilizado para sua leitura, o hardware e a data da análise (Tabela 2). Essas informações foram importantes, pois cada uma delas interfere de uma forma diferente na configuração do livro digital. A data de análise se fez necessária, pois os livros e softwares estão sujeitos a atualizações constantes, portanto, essa informação auxilia na identificação posterior de qual versão do livro foi analisada.

Tabela 2 - Identificação II

\begin{tabular}{|c|c|c|c|}
\hline \multicolumn{4}{|c|}{ IDENTIFICAÇÃO } \\
\hline \multicolumn{4}{|c|}{ Foi analisado em: } \\
\hline Formato & Software & Hardware & Data da análise \\
\hline$x x x x x$ & $x x x x x$ & $x X X X X$ & DD/MM/AAAA \\
\hline
\end{tabular}

Fonte: Elaborado pelo autor, com base na pesquisa realizada.

O próximo item da tabela marcou a existência ou não do número ISBN ou de outro número de identificação regulamentado (Tabela 3 ). Julgou-se interessante perceber quantos livros digitais dispunham dessa identificação, já que a UNESCO (1964) e a ABNT (2006) exigem que o conteúdo disponibilizado tenha ISBN para ser considerado livro9. A partir desse quesito se convencionou, para o preenchimento da tabela, a utilização dos números ' 0 ' ou ' 1 '. Para o caso de resposta positiva marcou-se ' 1 ', quando não existia ou não era encontrado, foi sinalizado ' 0 '. No caso da ausência do ISBN, mas a presença de outro número de identificação, a resposta foi considerada positiva. Também vale ressaltar que todas as categorias da tabela não são mutuamente excludentes.

Tabela 3 - Identificação III

\begin{tabular}{c}
\hline IDENTIFICAÇÃO \\
\hline ISBN \\
\hline $1 / 0$ \\
\hline Fonte: Elaborado pelo autor, com basenapesquisa realizada.
\end{tabular}

Fonte: Elaborado pelo autor, com base na pesquisa realizada.

A seguir, na macrocategoria "Acesso", foram investigadas as formas de acesso aos livros digitais (Tabela 4). Duas subcategorias foram criadas para indicar em que software o material era lido e se o seu conteúdo era acessado online ou off-line. A primeira delas, advinda da pergunta "De que forma o conteúdo é acessado?", foi dividida em quatro subdivisões: Software reader, Aplicativo próprio, Navegador e Outro. No caso do e-reader, onde o próprio sistema operacional é dedicado à leitura, foi marcada a primeira opção (Software reader). O aplicativo próprio foi marcado tanto

\footnotetext{
${ }^{8} \mathrm{Nem}$ todos os arquivos deixavam claro o tipo de formato em que eram apresentados, sendo que, nesses casos, fez-se uma estimativa de qual formato seria (em função de suas características e do software que permitia sua leitura) e incluiu-se junto ao nome um ponto de interrogação entre parênteses.

${ }^{9}$ Desde 2005 já está sendo realizada essa identificação para as publicações digitais (ISBN, 2010).
} 
quando o aplicativo era apenas um livro, como também nos casos deste abranger uma biblioteca que disponibilizou vários livros de sua coleção. O item Navegador serviu para confirmar que o livro pode ser lido através do próprio navegador, e a opção Outro se destinou a informar que o mesmo não se enquadrou em nenhum dos casos previstos, sendo sua forma de acesso ser explicitada nos comentários ${ }^{10}$.

A segunda subcategoria intitulada "O conteúdo é facilitado para..." diz respeito à necessidade do uso da internet para ter acesso à obra. A palavra 'facilitado' foi incluída para caracterizar a existência de uma indicação de que deveria ser feito o download do arquivo. Desse modo, nos livros que podem ser lidos tanto online quanto off-line, foram marcadas as duas opções; porém, no caso de possuírem conteúdos híbridos, ou seja, que o livro seja baixado para o hardware do leitor, mas alguns conteúdos só possam ser acessados quando conectados à rede, ou vice-versa, marcouse a terceira opção (off-line + com conteúdos online).

Tabela 4 - Acesso

\begin{tabular}{|c|c|c|c|c|c|c|}
\hline \multicolumn{7}{|c|}{ ACESSO } \\
\hline \multicolumn{4}{|c|}{ De que forma o conteúdo é acessado? } & \multicolumn{3}{|c|}{$\begin{array}{c}\text { O conteúdo é facilitado } \\
\text { para ... }\end{array}$} \\
\hline Software reader & $\begin{array}{l}\text { Aplicativo } \\
\text { próprio }\end{array}$ & Navegador & Outro & Online & Off-line & $\begin{array}{c}\text { Off-line }+ \\
\text { online }\end{array}$ \\
\hline $1 / 0$ & $1 / 0$ & $1 / 0$ & $1 / 0$ & $1 / 0$ & $1 / 0$ & $1 / 0$ \\
\hline
\end{tabular}

Fonte: Elaborado pelo autor, com base na pesquisa realizada.

A próxima macrocategoria abrangeu as funcionalidades do livro. Esse grupo foi dividido em três partes: Ações semelhantes às do livro impresso (Tabela 5); Ações que não podem ser realizadas no papel (Tabela 6); e Presença de atividades lúdicas ou de aprendizagem (Tabela 7).

No item referente às ações semelhantes ao livro impresso, foram analisadas as possibilidades de interatividade existentes no livro digital que repetem as mesmas ações que o leitor pode fazer em um livro impresso. Esta subcategoria foi composta com os elementos: "avanço da leitura" (caracteriza que o leitor pode avançar o conteúdo, seja através da rolagem, da troca de página etc.); "marcação de páginas" (é possibilitado que o mesmo adicione marcadores de página nas partes desejadas); "destaque de trechos" (é permitido grifar ou destacar trechos); "adição de comentários" (possibilita adicionar notas ou comentários).

Tabela 5 - Funcionalidades I

\begin{tabular}{cccc}
\hline \multicolumn{4}{c}{ FUNCIONALIDADES } \\
\hline \multicolumn{4}{c}{ Ações semelhantes às do livro impresso } \\
\hline Avanço da leitura & Marcação de páginas & Destaque de trechos & Adição de comentários \\
\hline $1 / 0$ & $1 / 0$ & $1 / 0$ & $1 / 0$ \\
\hline
\end{tabular}

Fonte: Elaborado pelo autor, com base na pesquisa realizada.

Dentre as ações que não podem ser realizadas no papel, mas que são possíveis de efetivar-se no meio digital, foram destacadas algumas facilidades que normalmente

\footnotetext{
${ }^{10}$ No software Microsoft Excel, onde foram realizadas as análises, é possível adicionar um comentário à célula. Quando esta possui um comentário, isto é indicado através de um triângulo vermelho que aparece no canto superior direito da célula e, para acessá-lo, basta passar o mouse em cima do mesmo, que logo é visualizado o comentário. Esse recurso foi utilizado para inserir observações pessoais no momento do preenchimento da tabela, para facilitar a compreensão da análise dos dados.
} 
estão relacionadas ao ato de ler: a ferramenta de busca por palavras e trechos específicos; o dicionário embutido, que permite a consulta ao significado da palavra sem ter que sair do livro; a existência de zoom, possibilitando aumentar imagens, tabelas, gráficos e textos e, ainda, a marcação automática, que ocorre no ato de fechar o livro, marcando o local onde a leitura foi interrompida. Ressalva-se que a menção à ampliação de textos se refere a textos tratados como imagem, como no caso do arquivo PDF, em que o layout do texto é fixo.

Tabela 6 - Funcionalidades II

\begin{tabular}{cccc}
\hline \multicolumn{4}{c}{ FUNCIONALIDADES } \\
\hline \multicolumn{4}{c}{ Ações que não podem ser realizadas no papel } \\
\hline $\begin{array}{c}\text { Busca por palavra ou } \\
\text { trecho }\end{array}$ & $\begin{array}{c}\text { Consulta ao dicionário } \\
\text { embutido }\end{array}$ & $\begin{array}{c}\text { Ampliação de imagens, } \\
\text { textos etc. (zoom) }\end{array}$ & $\begin{array}{c}\text { Marcação automática do } \\
\text { andamento da leitura }\end{array}$ \\
\hline $1 / 0$ & $1 / 0$ & $1 / 0$ & $1 / 0$ \\
\hline
\end{tabular}

Fonte: Elaborado pelo autor, com base na pesquisa realizada.

O próximo item também contempla as Funcionalidades e foi intitulado "A Presença de atividades lúdicas ou de aprendizagem". A intenção deste tópico foi a de avaliar os materiais extras que podem estar presentes no livro digital. A partir da observação dos artefatos - na codificação aberta - percebeu-se que muitos deles possibilitavam ao leitor mexer nos elementos das páginas e, inclusive, desenvolver atividades junto com a história ou em outro momento. Por este motivo, optou-se por separar esta categoria em três subcategorias. As duas primeiras destinaram-se a demarcar as atividades lúdicas e/ou de aprendizagem apresentadas ao leitor, sendo a primeira referente a atividades contidas dentro da história; e a segunda a atividades oferecidas como material extra. Julgou-se necessário separar ações que estavam dentro ou fora da história, por entender-se que isto interfere no contexto da atividade. A terceira categoria englobou os outros tipos de materiais extras que faziam parte do livro digital e que não eram necessariamente atividades a serem desenvolvidas, tais como vídeos, músicas, indicações de sites, texto complementar etc..

Tabela 7 - Funcionalidades III

\begin{tabular}{ccc}
\hline \multicolumn{3}{c}{ FUNCIONALIDADES } \\
\hline & Presença de atividades lúdicas ou de aprendizagem \\
\hline Dentro da história & Fora da história (Material extra) & Outros tipos de materiais extras \\
\hline $1 / 0$ & $1 / 0$ & $1 / 0$ \\
\hline
\end{tabular}

Fonte: Elaborado pelo autor, com base na pesquisa realizada.

A macrocategoria "Potencialidades do meio digital" foi dividida em três grupos, sendo que o primeiro abrangeu ações relacionadas com a interatividade do livro (Tabela 8); o segundo foi específico para as linguagens da multimídia (Tabela 9), e o terceiro dizia respeito à possibilidade de interação entre os leitores (Tabela 10).

No primeiro grupo foram analisados alguns elementos que proporcionaram a interatividade no livro. Nesta subcategoria, primeiramente se verificou a existência de recursos multimídia que necessitavam ser acionados pelo leitor, ou seja, que um possível som, movimento e/ou alteração da cena ou da história só iniciasse mediante uma ação do leitor (toque na tela, clique do mouse, movimentação do aparelho etc.); em caso contrário, a leitura seria efetivada sem esses recursos multimídia. 
A segunda e a terceira subcategorias eram relacionadas ao hipertexto. A segunda diz respeito a aspectos da narrativa, especialmente o uso da hipertextualidade, ou seja, se esta poderia conduzir o leitor por diferentes caminhos, traçando uma história diferente que dependeria das suas opções para ser conduzida. Verificou-se, ainda, se os textos que compõe o livro poderiam ser lidos em qualquer ordem sem, entretanto, prejudicar a compreensão geral do mesmo. Para que isto acontecesse o conteúdo deveria ser apresentado de forma que o leitor não fosse induzido a uma sequência específica. A terceira foi colocada a fim de que fosse verificado se, em algum momento do livro, estava prevista a conexão entre partes deste através do hipertexto ou de um hiperlink que direcionasse para um site.

A quarta subcategoria versou sobre a customização do livro. Aqui foi avaliada a existência da possibilidade de o leitor alterar os elementos visuais deste artefato. Dentre as possibilidades mais usuais de alterações a serem realizadas pelo usuário, pode-se citar: o tamanho da fonte (diferente do zoom, que faz com que o texto se reconfigure na tela), a tipografia, as cores do fundo do texto, o tamanho das margens e o espaçamento entrelinhas. Se o livro possibilitou pelo menos uma dessas alterações, a customização foi considerada presente na obra analisada.

Tabela 8 - Potencialidades do meio digital I

\begin{tabular}{cccc}
\hline \multicolumn{4}{c}{ POTENCIALIDADES DO MEIO DIGITAL } \\
\hline \multicolumn{4}{c}{ Interatividade } \\
\hline Multimídia acionada pelo leitor & Narrativa hipertextual & Hipertexto e hiperlink & Customização \\
\hline $1 / 0$ & $1 / 0$ & $1 / 0$ & $1 / 0$ \\
\hline
\end{tabular}

Fonte: Elaborado pelo autor, com base na pesquisa realizada.

O segundo grupo destacado dentro de 'Potencialidades do meio digital' foi a Multimídia. Aqui se efetivou uma avaliação sobre a existência e exploração de multimídia no interior do livro (sem considerar a capa). Para avaliá-la, fez-se uma divisão sobre as diferentes linguagens que poderiam formá-la. Uma classificação geral seria: texto, imagem e som; no entanto isso não foi suficiente para demarcar as especificidades dos livros digitais. Portanto, separou-se em: texto; cores (aplicada ao texto e/ou imagem); imagem estática (ilustração ou foto); imagem em movimento (animação ou vídeo); trilha sonora (música e/ou som que acompanham toda a narrativa); som em momentos específicos da história (ou de algum personagem específico); narração; e outro (quando não se adequasse a nenhuma das opções anteriores).

Tabela 9 - Potencialidades do meio digital II

\begin{tabular}{cccccccc}
\hline \multicolumn{7}{c}{ POTENCIALIDADES DO MEIO DIGITAL } \\
\hline Texto & Cores & $\begin{array}{c}\text { Imagem } \\
\text { estática }\end{array}$ & $\begin{array}{c}\text { Imagem em } \\
\text { movimento }\end{array}$ & $\begin{array}{c}\text { Trilha } \\
\text { sonora }\end{array}$ & $\begin{array}{c}\text { Som em momentos } \\
\text { específicos }\end{array}$ & Narração & Outro \\
\hline $1 / 0$ & $1 / 0$ & $1 / 0$ & $1 / 0$ & $1 / 0$ & $1 / 0$ & $1 / 0$ & $1 / 0$ \\
\hline
\end{tabular}

Fonte: Elaborado pelo autor, com base na pesquisa realizada.

A outra potencialidade verificada abrangeu a Interação entre leitores mediada pela tecnologia digital. Esta categoria foi dividida em três quesitos. O primeiro deles indicou a possibilidade de compartilhamento de trechos da história (por e-mail, redes sociais etc.), facilitada por algum atalho, ícone ou botão no livro ou software de leitura. 
No segundo observou-se a possibilidade de, durante a leitura do livro, o leitor conseguir ver destaques e/ou comentários feitos por outros usuários (categorizados como anônimos ou não). O terceiro e último quesito diz respeito à possibilidade de se estabelecer uma discussão online sobre um livro, durante sua leitura, ou seja, se era possível, a troca de comentários e/ou destaques simultâneos entre os leitores, no momento em que estes estão sendo feitos.

Tabela 10 - Potencialidades do meio digital III

\begin{tabular}{ccc}
\hline \multicolumn{3}{c}{ POTENCIALIDADES DO MEIO DIGITAL } \\
\hline \multicolumn{3}{c}{ Interação entre leitores } \\
\hline $\begin{array}{c}\text { Compartilhar trechos com outros } \\
\text { leitores }\end{array}$ & $\begin{array}{c}\text { Ler destaques e/ou comentários de } \\
\text { outros leitores }\end{array}$ & $\begin{array}{c}\text { Troca entre leitores de } \\
\text { comentários e/ou destaques }\end{array}$ \\
\hline $1 / 0$ & $1 / 0$ & $1 / 0$ \\
\hline
\end{tabular}

Fonte: Elaborado pelo autor, com base na pesquisa realizada.

A próxima macrocategoria contemplou a remediação do livro impresso (Tabela 11), na qual se investigou se os livros digitais estão se aproximando ou se distanciando do seu análogo em papel. Para essa fase, foram estabelecidos quatro parâmetros para avaliação: Aparência, Estrutura, Navegação linear e Ênfase no texto escrito.

Para avaliar a aparência, verificou-se a presença de imitações da materialidade do livro, como representação de suas páginas, do som emitido ao folheá-las quando em papel etc.. No quesito estrutura, buscou-se a existência de elementos pré-textuais, textuais e pós-textuais, que estivessem bem organizados e que fossem identificados claramente. Esses elementos foram definidos conforme a síntese construída com base em Haslaw (2007), Hendel (2006) e Fontoura (2007). Para manter a classificação binária e evitar o excesso de subcategorias, selecionaram-se os itens essenciais à estrutura do livro. São eles: a capa, a folha de rosto, a página de créditos, o sumário, um elemento pós-textual e, obviamente, a parte textual. A opção por não delimitar os elementos pós-textuais para avaliação baseou-se no fato de que estes variam conforme o gênero de leitura. Também vale destacar que a página de créditos e o sumário podem vir tanto no início quanto no final do livro e quando apresentados no final, podem ser considerados como elementos pós-textuais.

Optou-se por inserir a navegação linear nesta macrocategoria de remediação, pelo fato da encadernação e numeração de páginas do livro induzir a uma leitura linear. Consequentemente, aqueles conteúdos que mantiveram a ordem de navegação, sempre horizontal ou vertical, causando a sensação de uma leitura linear, mantêm a ideia de livro 'tradicional'. Os outros, que alteraram essa navegação, ora se movimentando de forma horizontal, ora vertical, ou, ainda, que propuseram outro tipo de navegação, como janelas que surgem de alguma forma etc., se distanciam da navegação linear do impresso. Vale lembrar que neste item foi avaliada a sensação de linearidade. Essa sensação, em um livro digital, pode ocorrer mesmo em um conteúdo que contenha narrativa hipertextual. Diferente do livro impresso, no qual o leitor teria que pular páginas ou ir para uma página específica indicada para seguir a história conforme sua escolha - avançando ou retornando no material encadernado; no meio digital essas opções podem ser exibidas linearmente, sendo exigida a tomada de decisão do usuário e, logo a seguir, como consequência, apresentada a resposta, causando a sensação de linearidade, mesmo que o leitor esteja consciente de que se trata de uma narrativa hipertextual e de que poderia haver outras opções. 
O último quesito desta categoria focalizou a ênfase no texto escrito ou o uso de outros recursos para dar apoio ao texto, sem tirar-lhe a prioridade. No caso de livros ilustrados, tanto no meio impresso como no meio digital, a imagem divide a atenção com o texto e, para esses casos, a ênfase no texto escrito foi marcada como positiva, uma vez que a imagem e o texto estavam equiparados. Se a imagem foi percebida como elemento principal e o texto como seu apoio (legenda explicativa, comentário etc.), a resposta negativa a esse quesito foi negativa.

Tabela 11 - Aproximação da ideia de livro impresso (remediação) APROXIMAÇÃO DA IDEIA DE LIVRO IMPRESSO (REMEDIAÇÃO)

\begin{tabular}{cccc}
\hline Aparência & Estrutura & Navegação linear & Ênfase no texto escrito \\
\hline $1 / 0$ & $1 / 0$ & $1 / 0$ & $1 / 0$ \\
\hline
\end{tabular}

Fonte: Elaborado pelo autor, com base na pesquisa realizada.

A última macrocategoria abordou o projeto gráfico do livro digital. Esta macrocategoria foi dividida em Miniatura da capa, Capa, Aplicação consistente de estilos e espaçamentos, Projeto gráfico específico para o meio digital, Fonte da editora, e Customização sem perda de informações visuais (Tabela 12).

Na miniatura da capa foi avaliado se ela estava coerente com o layout da capa principal. O livro foi considerado um exemplar com capa quando possuía uma imagem $^{11}$ de abertura com titulo, autor e editora.

No item referente à 'Aplicação consistente de estilos e espaçamentos', pretendeu-se avaliar a formatação do texto, ou seja, as diferenciações dos títulos, a hierarquização visual das informações de acordo com seu nível de importância, a utilização dos espaços em branco, etc..

A categoria 'Projeto gráfico específico para o meio digital' foi criada para que se pudesse averiguar se e em que medida as características do meio digital foram consideradas no momento do projeto gráfico. Para a compreensão dessa diferença, foi utilizada a conceituação de suporte e portador de Ribeiro (2010). Para a autora, display é uma tela ou superfície de qualquer natureza nas quais são exibidos textos/imagens, por exemplo: outdoors, rótulos, tela de televisão, tela de celular etc.. O display pode ser um suporte ou um portador. O suporte é um display que contém texto/imagem que foram projetados para serem exibidos nesse display; e o portador seria aquele display que acolhe um texto/imagem que não tenha sido projetado para ser exibido nessa superfície/tela. Para melhor compreensão, pode-se exemplificar com uma notícia no jornal, neste caso o papel jornal é um suporte. Se a mesma notícia fosse fotocopiada em um xerox, o papel ofício do xerox seria um portador, pois a configuração visual da notícia não foi projetada para ser apresentada dessa forma. A mesma analogia pode ser feita nos aparelhos digitais. Assim, o que se verificou com essa categoria foi se o meio digital funcionava como um portador ou um suporte.

Outro parâmetro relacionado ao projeto gráfico foi a 'customização do conteúdo sem perda de informações visuais'. Este item diz respeito à manutenção das hierarquias do texto mesmo quando é possibilitado ao leitor que altere as configurações tipográficas. Especificando melhor, se houver negrito, itálico ou outro destaque tipográfico, essas especificações devem ser mantidas, mesmo que o texto seja customizado pelo usuário. Quando um livro pôde ser customizado e trouxe, além

\footnotetext{
${ }^{11}$ Por imagem se compreende também a utilização de cores e tipografias, que diferenciam a capa de um exemplar específico das outras.
} 
das possíveis opções do software reader, a fonte original da editora, embutida no livro, este item foi marcado como positivo. Também foram considerados com resposta afirmativa, aqueles casos em que não existiu a possibilidade de customização da tipografia, mas que ficou subentendido que, como foi oferecida apenas uma fonte, esta seria a escolhida pela editora.

Além desses fatores, no último quesito se avaliou a qualidade da realização ou da execução do arquivo. Nesse item se investigou a presença de erros de funcionamento e/ou da apresentação visual do livro.

Tabela 12 - Projeto Gráfico de Interface

\begin{tabular}{|c|c|c|c|c|c|c|}
\hline \multicolumn{7}{|c|}{ PROJETO GRÁFICO DE INTERFACE } \\
\hline $\begin{array}{c}\text { Miniatura } \\
\text { da capa }\end{array}$ & Capa & $\begin{array}{c}\text { Aplicação consistente } \\
\text { de estilos e } \\
\text { espaçamentos }\end{array}$ & $\begin{array}{l}\text { Projeto gráfico } \\
\text { específico para o } \\
\text { meio digital } \\
\end{array}$ & $\begin{array}{c}\text { Fonte } \\
\text { da } \\
\text { editora }\end{array}$ & $\begin{array}{l}\text { Customização sem } \\
\text { perda de } \\
\text { informações visuais }\end{array}$ & $\begin{array}{l}\text { Qualidade de } \\
\text { realização do } \\
\text { arquivo }\end{array}$ \\
\hline $1 / 0$ & $1 / 0$ & $1 / 0$ & $1 / 0$ & $1 / 0$ & $1 / 0$ & $1 / 0$ \\
\hline
\end{tabular}

Fonte: Elaborado pelo autor, com base na pesquisa realizada.

Com a tabela construída, passou-se para a etapa que focalizou a análise da amostra. Para realizá-la, foram selecionados um tablet, um e-reader e um notebook. A escolha do modelo e marca de cada um deles ocorreu em função da conveniência da pesquisadora, por serem esses os aparelhos aos quais a mesma tinha acesso. Essa é uma estratégia bastante discutida pelos adeptos da pesquisa qualitativa, embora evidentemente as mesmas restrições na disponibilidade de equipamentos (e de outras naturezas) se imponham nos estudos quantitativos.

\section{CONCLUSÃO}

A tabela de análise final apresentou resultados satisfatórios. Foi possível perceber os recursos explorados nos e-books e, mais que isso, identificar tendências e características que atravessaram a amostra de modo bastante marcante. Sempre tendo em mente que o ponto de partida é um mapeamento, e não uma amostra com representatividade estatística, a intensidade de certas regularidades nas características gerais dos livros digitais permitiu identificar grupos com características em comum, sugerindo a pertinência de uma classificação inicial dos e-books a partir dos recursos explorados nos mesmos. A partir dessa análise mais geral, pode-se selecionar pontos específicos para um maior aprofundamento em estudos futuros, de ordem qualitativa, ou o uso do instrumento de análise aqui apresentado em pesquisas quantitativas, visando a generalização dos resultados.

\section{REFERÊNCIAS}

ABNT, Associação Brasileira de Normas Técnicas. NBR 6029 - Informação e documentação - Livros e folhetos - Apresentação. Rio de Janeiro, 2006.

BOLTER, J. David; GRUSIN, Richard. Remediation: Understanding New media. 2000.

BOLTER, Jay David. Writing Space: Computers, Hypertext, and the Remediation of Print. Routledge, 2001.

BRINGHURST, Robert. Elementos do Estilo Tipográfico. 3ạ ed. São Paulo: Cosac Naify, 2005. 
CHARTIER, Roger. A aventura do livro: do leitor ao navegador. São Paulo: Editora UNESP/Imprensa Oficial do Estado, 1999.

CHARTIER, Roger. A Ordem dos Livros. Lisboa: Vega, 1997.

FONTOURA, Antônio Martiniano. O livro do livro. Curitiba: Gramofone. 2007

FRAGOSO, Suely. De interações e interatividade. In: Revista Fronteiras Estudos midiáticos, São Leopoldo - RS, v. 3, n. 1, p. 83-95, 2001.

FRAGOSO, Suely; RECUERO, Raquel; AMARAL, Adriana. Métodos de Pesquisa para Internet. Ed. Sulina: Porto Alegre, 2012.

HENDEL, Richard. 0 design do Livro. 2a ed. Cotia: Ateliê Editorial, 2006.

ISBN, Agência Brasileira do ISBN. Publicações eletrônicas. 2010. Disponível em http://www.isbn.bn.br/website/publicacoes-eletronicas Acesso em 3 jan. 2014.

LANDOW, George P.. Hipertext 3.0: Critical Theory and New Media in an Era of Globalization. 3rd ed. Baltimore: The Johns Hopkins University Press, 2006.

LUDWIG, Fabiana. Os e-books infantis em análise. Florianópolis, 2012. Dissertação (Mestrado em Educação, Comunicação e Tecnologia) - Universidade do Estado de Santa Catarina. Orientador(es): Geovana Mendonça Lunardi Mendes.

PATTON, Michael Q. Qualitative research \& Evaluation Methods. 3a ed. London: Sage, 2002.

RIBEIRO, Ana Elisa. Do jornal impresso às telas digitais: trilhas do leitor. In: Comunicação e Sociedade, vol. 17, 2010, p. 73-86.

SEHN, Thaís Cristina Martino Sehn. Um livro, quatro formatos: as novas materialidades do conhecimento. In: Educação Gráfica, vol. 18, 2014, no 1, p. 6-25. Disponível em: < http://goo.gl/Nuoggl>. Acesso em 5 ago. 2014.

SEHN, Thaís Cristina Martino. As possíveis configurações do livro nos suportes digitais. Dissertação (Mestrado em Comunicação e Informação) - Faculdade de Biblioteconomia e Comunicação, Universidade Federal do Rio Grande do Sul. Orientador: Suely Fragoso. Disponível em: <http://goo.gl/ox2a85>. Acesso em 5 ago. 2014.

UNESCO, United Nations Educational, Scientific and Cultural. Organization records of the general conference: resolutions. Thirteenth Session. Paris, 1964. Disponível em: $<$ http://unesdoc.unesco.org/images/0011/001145/114581e.pdf\#page=144>. Acesso em 6 maio 2013. 